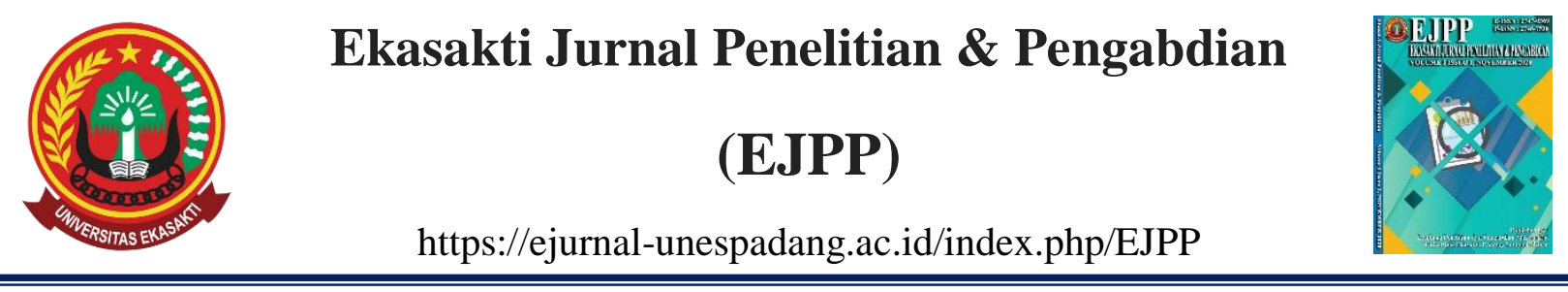

\title{
THE OMISSION OF GRAMMATICAL COMPONENTS: ERRORS AND ITS EFFECTS ON STUDENT'S ACADEMIC WRITING QUALITY
}

\author{
Zulfariati $^{1}$ \\ ${ }^{1)}$ Universitas Mahaputra Muhamad Yamin Solok \\ Email: zulfariatijun@gmail.com \\ INFO ARTIKEL \\ Received : 29/10/2021 \\ Revised : :16/11/2021 \\ Publish : :17/11/2021 \\ Keywords: \\ Grammatical Errors, \\ Omission, Academic \\ Writing Quality, \\ Corrections.

\begin{abstract}
Grammatical errors have been a major issue for decades. Some researchers have analyzed many types of grammatical errors made by foreign language students of English. This paper is one of the descriptions of grammatical errors derived and developed by the English Department of FKIP UMMY Solok in writing their theses. The students' theses which had been allowed for joining the final comprehensive exam for getting the strata one degree at English Department of FKIP UMMY Solok were analyzed. Ideally, those theses were written by using correct grammar. However, there were still many errors in those theses. The errors found were respectively in form of omission, addition, misformation, and misordering types. This article focuses on the description of the omission of grammatical components written by the students and how it affects their theses quality. Admittedly, these grammatical errors make the theses quality are low and the ideas of the writing are difficult to be caught by the readers because some of the head nouns, subjects, verbs, direct objects, and other components of some sentences in those theses were omitted. It is suggested that the lectures on Grammar and Writing subjects as well as the students' advisors on academic writings do intensive corrections towards students' theses.
\end{abstract}

DOI: https://doi.org/10.31933/ejpp.v2i1.475

\section{INTRODUCTION}

Academic writing is written by scholars for other scholars who involve college students as their community. It is devoted to topics and questions that are interesting to the academic community who write academic writings, especially theses. It should present the readers with the informed arguments. To construct informed argument and to widespread science and technology, college students should use correct grammar in writing their academic writings or theses which imply their grammar ability level.

At Universitas Mahaputra Muhammad Yamin Solok, West Sumatera, Indonesia academic writing in form of a thesis is one of the types of writings produced by the English Department students to promote their ideas in English language teaching and learning activities for getting the sarjana degree. However, it is found that many grammatical errors that had been made by the students in their writings. Although those theses had been agreed by students' 
advisors for joining the final comprehensive exam - the last exam for getting the sarjana degree, some of the sentences written in those theses were omitted some grammatical components. Many students omitted some grammatical components in some sentences. It makes one of the quality components of academic writing in terms of accuracy of the writing is not completed. Consequently, there is likely to be a serious loss of meaning. It happens because normally, they are afraid of making errors and worried about their capacity in selecting and organizing words to produce sentences. Those feelings seem to make the students self-doubting in making up their writings. Having a little confidence can make them unenthusiastic to try to write, even hate writing and show some kind of resistance (Ibrahim \& Ibrahim, 2020)

Academically, this may be because in writing academic writings, the students should use complete and appropriate grammar. After all, in English, grammar is one of the components of language which is used to give meaning to the structure of a language. The writing process involves the compilation of texts as well as orthography and grammar. The right meaning of words, grammatically correct spelling, and correct syntax and grammar contractions must be acquired to attain good penmanship (Uibu and Liiver, 2015). Therefore grammar is the essential part of the use of language process, especially in written language. It is the description of how the language uses patterns of structure to convey the meaning. It also serves to enhance and sharpen the expression of meaning. So, by using a good grammar system of a language, it will help deliver ideas, messages, and feelings either to the listeners or readers. It means that since there are grammatical errors in using language, especially in academic writing, it will result in disorganized writing and will cause some communicative problems.

One of the effects causes by the grammatical errors in using language in academic writing is the accuracy of the meaning of the ideas presented. Accuracy is only one aspect of the total fabric of good writing. In some cases, few teachers will be concerned by one minor mistake with a preposition or plural in a sentence. However, if a student is making mistakes in every other word there is likely to be serious confusion about meaning so that the ideas written in the academic writing will be ambiguous. This condition may happen to many non-native users of English. They tend to have problems are related to their mother tongue. Japanese speakers, for example, find it difficult to use articles in English because these are not found in Japanese. It is unrealistic for overseas students to expect to reach 100\% accuracy (and many native English speakers have similar difficulty). However, they should aim to steadily improve their accuracy, to make their work as clear and readable as possible. The components of accuracy in writing have been chosen on the basis that they regularly cause difficulty and confusion in students' writing (Bailey, 2006).

The above conditions, the difficulties of having the accuracy, did happen to the English Department students at Universitas Mahaputra Muhammad Yamin Solok, West Sumatera, Indonesia, in producing their academic writings. They omitted the head nouns, subject, verbs, direct objets, and some other grammatical components in some sentences they have written. They made the errors on the type of omission based on Surface Structure Taxonomy classified by Dulay (1982: 154). It makes their writing results quality is scientifically confused. Therefore, it 
is highly necessary to describe these errors, the ones in form of the omission of grammatical components, to be analyzed and corrected and to know why the students did make these errors. So, this paper specifically discusses the types of omission errors in the sentences of academic writings or theses, how it affects the quality of their academic writings or theses, and what the students' academic writings or theses advisors should do to overcome the grammatical problems in students' academic writings to have high-quality academic writings.

Following the problems above, logically this paper is highly necessary to discuss the effects of grammatical errors, in the omission type, on students' academic paper quality. The quality is indicated by some indicators such as accuracy, English academic style and language, academic vocabulary, cautious writing, and grammar.

The data and information presented in this paper were collected by doing content analysis procedures. These data were mainly collected from 12 theses written by English Department students of Universitas Mahaputra Muhammad Yamin Solok. These 12 theses were agreed by their advisors to follow the final comprehensive exam. They were used totally to see the grammatical errors made by the students and to see their effects on the quality of academic writings or theses.

1. Grammar

The term of grammar, in this case, English grammar comprehensively has various meanings (Quirk, et al, 1985: 12). It includes syntax and that aspect of morphology (the internal structure of words) that deals with the inflection. In detail, grammar is identified with inflections. Grammar is the system of rules governing the conventional arrangement and relationship of words in a sentence. Technically, grammar refers to sentence-level rules only, and not to rules governing the relationship among sentences, which refers to discourse rules (Brown, 2001: 362).

In another concept, the word grammar has been used so far to an aspect of how a language, in this case, English is conventionally used, i.e. to the structure or system of a particular language. However, it is a slippery word and is also used to refer to the way that linguists describe the system (Cameron, 2001). Additionally, in the case of communication, grammar is a resource for communication, the adaptation of lexis. In other words, grammar is regarded as an aid to language users in accurately communicating their messages, not as some isolated body of knowledge that must be studied for its own sake (Frodesen, 1991: 264). He stresses that grammar as a component of language enables people to make their meanings clear and precise.

2. Grammatical Error

The term of grammatical error is highly defined in some ways. Errors are breaches of code. They are not physical failures, but a sign of imperfect knowledge of the code. Errors deviate from what is regarded as the norm (Corder, 1973). In some conditions, errors are believed to be an indicator of the learners' stages in their target language development. From the errors that learners commit, one can determine their level of mastery of the language system (Lengo, 1995). Even though, it is explained that errors would appear to demonstrate 
a fault at a deeper level something that has not been learned or assimilated or whose correct version is unknown, indeed, an error may have become so ingrained that a student may not even have perceived it as such and is thus condemned to repeat it until proficiency do them part (Porte, 1993).

In some research findings, it is found that errors are related to linguistic factors. These include inter-language (L1 interference), the general order of difficulty (hierarchy of difficulty) which applies to both L1 and L2, the morphemes theory that discusses what is learned before the other (as some morphemes are more difficult than others), and finally, there is intra-lingual (Target Language source like regular form: within the target language). Examples of intra-lingual sources include overgeneralization, incomplete applications of rules, and false concepts hypothesized. Nor must we forget to say here that redundancy reduction or false analogy is in a way similar to overgeneralization and one of the causes of it. However, addition and omission are also some types of redundancy (Al-Yaari, 2013).

Moreover, it is also found that errors are related to non-linguistic factors too. These are errors resulting from different things like teaching methodology/ technique, translation(conscious interference), learner's age considering $\mathrm{CPH}$, learning strategy(like the way Arabic grammar is taught in ALI), communication strategy (like when these ASL learners make mistakes and Saudi native speakers agree with them), carelessness(when some ASL learners know the rule but do not apply it), language creativity, like using Arabic rules by making a false analogy with those rules in their language (Al-Yaari, 2013).

3. Academic Writing

Understanding academic writing is academically needed by the students. According to Bailey (2003: 1), academic writing is designed for anybody who is studying at Englishmedium colleges and universities and has to write essays or other assignments for exams or course work. Academic writing is a flexible course that allows students to work either with a teacher or by themselves, to practice those areas which are most important for their studies.

The purpose of academic writing is to explain something or to give information about something. Academic writing requires certain skills. These skills include sentence structure (how to arrange words in a sentence), organization (how to arrange ideas in a paragraph), and, of course, grammar and punctuation (Hogue, 2008: 2). The students may have to produce various types of writings as part of their courses. Some of the terms used to describe different types of writing assignments can be confusing. So, the students need to be clear about the basic components of written texts (Bailey, 2003: 3).

4. Academic Writing Quality

The academic writing quality is indicated by some characteristics, such as accuracy, English academic style, and language, cautious writing, academic vocabulary, grammar, and organization. 


\section{Accuracy}

Accuracy is only one aspect of the total fabric of good writing. Few teachers will be concerned by one minor mistake with a preposition or plural in a sentence. However, if a student is making mistakes in every other word there is likely to be serious confusion about meaning so that the teacher is unable to mark the work fairly. Even though non-native users of English tend to have problems that relate to their mother tongue, and it is unrealistic for overseas students to expect to reach 100\% accuracy (and many native English speakers have similar difficulty), they should aim to steadily improve their accuracy, to make their work as clear and readable as possible. The components in Accuracy in Writing have been chosen on the basis that they regularly cause difficulty and confusion in students' writing (Bailey, 2006).

6. English Academic Style and Language

The style of English academic writing is formal. Its main characteristics are the absence of conversational features and the use of an appropriate academic vocabulary. Developing command of formal style is extremely important for nonnative speakers wishing to master the conventions of English academic discourse (Yakhontova, 2003).

7. Cautious Writing

An important feature of English academic written discourse is a cautious manner of writing. It is the avoidance of too definite statements or conclusions. The purpose of such a strategy is to be accurate and to protect the author from being criticized for possible errors or invalid claims. Cautious writing also allows for other opinions or points of view. The main linguistic ways of doing this are as follows: 1) By using modal verbs, 2) By using adjectives that express probability, 3) By using a there is construction with the word possibility, 4) By using adverbs that express certainty and probability, 5) By using verb phrases that distance the writer from the statements or conclusions he/she makes, 6) By using quantity words, and 7) By using statements of shared knowledge, assumptions, and beliefs (Yakhontova, 2003).

8. Academic Vocabulary

Another important feature of English academic writing is a tendency to choose more formal alternatives when selecting words of different parts of speech. 1) Verbs. English academic style makes use of formal verbs, often of Latin origin. In Ukrainian textbooks, such verbs are usually referred to as "general scientific verbs", 2) Collocations. Collocations are relatively stable word combinations that occur regularly. Writers' knowledge and appropriate use are very important for successful academic writing in English, 3) Logical Connectors. Logical connectors (transitional expressions) are linking words and phrases which establish the logical relationship between ideas within a sentence or between sentences. They also improve the flow of writing, which is a smooth movement from one idea or piece of information in a text to the next. Logical connectors are thus guideposts for readers that help them to better follow the text. As transitional expressions show various kinds of logical relations, they may be grouped according to their meaning and function (Yakhontova, 2003). 


\section{Grammar Components}

There is a need to review grammar as the theme that usually causes problems for learners. The areas are widely covered and are considered here. They are: 1) Word order. A normal English declarative sentence has the following structure, with the subject preceding the predicate, 2) Agreement of Subject and Verb. The subject and the main verb of a sentence (clause) must agree in number, 3) Nouns Keeping Foreign Plurals. Plurals of the nouns of Latin, Greek, and Hebrew origin are often used in English scientific writing (Maclin, 1996) even though their English plurals may exist in general use, 4) Articles. English articles usually are widely taught. Below are the most basic rules of using articles that you should always observe: The Indefinite Article " $a$ " (before a consonant sound) or "an" (before a vowel sound) is used with countable nouns in the singular, meaning "member of a class of objects," "one of," "some", The Definite Article the is used with countable nouns in the singular/plural and uncountable nouns in the meaning "contextually known," "mentioned earlier," and The Zero Article. Usually, no article is used when a plural or an uncountable noun is mentioned first unless the special conditions for definite article use apply (Yakhontova, 2003).

Besides the above grammar components, another component of grammar is indicated as the indicator of academic writing quality. The component of grammar is sentence structure, including 1) Simple, 2) compound, 3) complex, and (4) compound-complex Sentences. A simple sentence is a sentence that has one subject-verb pair. The word simple in "simple sentence" doesn't mean "easy." It means "one subject-verb pair." The subject in a simple sentence may be compound, like My brother and I are completely different. The verb in a simple sentence may be compound, for example, They laughed and cried at the same time. However, each sentence is a simple sentence because it has only one subject-verb-pair (Hogue, 2008).

In another case, there is sentence combining. It is a way to improve the writer's sentence-writing skills. In doing a sentence-combining exercise, the writer combines two (or more) short sentences into one longer sentence. All the long sentences together make a paragraph. There may be several correct ways to combine the sentences. However, there are a few rules to follow: 1) Do not repeat words if possible, for example, do not repeat $I \mathrm{am}, 2$ ) Omit words, but don't leave out any important information, change words, for example, change a noun to a pronoun or make a singular word plural, 4) Add words, for example, add the connecting word and. The goal is to write smooth, grammatically correct sentences that contain all the information but do not repeat any of it. The example can be:

a. I am a man.

b. I am famous.

Combined sentence: I am a famous man.

I am a man and I am famous is a grammatically correct sentence, but a native speaker would not write it because a native speaker would not repeat the words I am. Another possible sentence is I am a man who is famous (Hogue, 2008). 
10. Organization

The organization is one of the most important writing skills. A well-organized paragraph is easy to read and understand because the ideas are in a recognizable pattern. Just as you organize tools on a workbench or clothes in a closet, you also organize sentences in a paragraph. Listing order is a pattern often used in English (Hogue, 2008).

\section{RESEARCH METHODS}

This research was conducted as library research by applying the content analysis procedures. This research was aimed at identifying the types and percentage of students' grammatical errors in writing their academic writing in form of theses which had been agreed by their advisors for joining the final comprehensive exam. There were 12 (twelve) of students' academic writings in form of theses of the English Department students of FKIP UMMY Solok which had been analyzed.

\section{RESULTS AND DISCUSSION}

\section{Results}

Based on the result of the research, it is found that there are four groups of grammatical errors based on Surface Structure Taxonomy (Dulay, 1982: 150) on those academic writings in form of theses as presented in the following table. They are respectively in form of omission, addition, misformation, and misordering types. However, the omissions errors are at high percentage errors found in the students' academic writings in form of theses. This type of errors needed to be analyzed and corrected as well as to find out its causes.

Table 1. The Types and Level of the Students' Grammatical Errors

\begin{tabular}{clccc}
\hline No & $\begin{array}{c}\text { The Types of Errors } \\
\text { (Categories of Errors) }\end{array}$ & $\begin{array}{c}\text { Total Frequency } \\
\text { of Errors }\end{array}$ & $\begin{array}{c}\text { Percentage of } \\
\text { Errors }\end{array}$ & $\begin{array}{c}\text { Level of } \\
\text { Students' Errors }\end{array}$ \\
\hline 1 & Omissions & 1.081 & $81.29 \%$ & Very high \\
\hline 2 & Additions & 108 & $8.12 \%$ & Low \\
\hline 3 & Misformations & 104 & $7.82 \%$ & Low \\
\hline 4 & Misorderring & 37 & $2.79 \%$ & Low \\
\hline & Total number of Errors & 1.330 & $100 \%$ & \\
\hline
\end{tabular}

Based on the table above the omission type of error is the highest level of errors made by the students. The followings are some grammar errors taken from grammar errors identified in students' final academic writings in form of theses. Some of the examples of errors identified on the students' academic writings in form of theses in the omission type-the omission of major constituents types are as in the following (the number in brackets at the end of the example refers to the students' academic writings in form of theses):

1. Omission of Head Noun

a. Writing is difficult because the students have to develop ideas by their own...... (1- p.1);

b. As soon as the teacher finishes reading the piece......., she/he should explain, analyze, and discuss every sentences. (2-p14.); 
c. He said that mastery of vocabulary is necessary thing in learning foreign ....... since it is needed to communicate effectively. (3-p.7).

In sentence a the head noun should be completed to make the sentence is grammatically acceptable. This sentence can be completed by adding the head noun ideas. In sentence $\mathbf{b}$ the head noun should be completed to make the sentence is grammatically acceptable. This sentence can be completed by adding the head noun reading text in a sentence. At last in sentence $\mathbf{c}$ the head noun should be completed to make the sentence is grammatically acceptable. This sentence can be completed by adding the head noun language.

The above sentences are the data collected based on the students' academic writings in form of theses. Based on the data above, it was found that the students significantly tended to ommit the head noun that should be put on the blank spaces. Due to the omission errors, consequently the ideas of each sentence above will be loosing. It makes the accuracy of the sentences is low. Since complete grammar is one of the indicators of academic paper quality (Yakhontova, 2003), scientifically, the quality of academic writing will be lower than what it should be (Hogue, 2008).

2. Omission of Subject

a. While the student study about vocabulary.......not study it only from dictionary but also trhough context or stories. (3-p.17);

b. Actually, the sort of task that....... choose, depend on a view of language teaching. (4p.4);

c. Finally, teacher is a source of knowledge and direction, because in writing diary...... need teacher's guidance and here is the teacher's role to help them. (5-p.13).

In sentence a the subject should be completed to make the sentence is grammatically acceptable. This sentence can be completed by adding the subject "they do". In sentence b the subject should be completed to make the sentence is grammatically acceptable. This sentence can be completed by adding the subject "the teachers". Then in sentence c the subject should be completed to make the sentence is grammatically acceptable. This sentence can be completed by adding the subject "the students".

In the above sentences, it is found that the students significantly tended to ommit the subjects of the sentences that should be put on the blank spaces. Because they omitted them, consequently the ideas of each sentence above are lost. It makes the accuracy of the sentences is low. So, scientifically, the quality of academic writing will be lower too than what it should be.

3. Omission of Main Verb

a. She could not ....... any cheese in it. (3-p13);

b. Give a short conclusion about the story in order to ....... the students do not confused about the story. (7-p.11).

In sentence a the main verb should be completed in order to make the sentence is grammatically acceptable. This sentence can be completed by adding the main verb "be 
have". Then, in sentence $\mathbf{b}$ the main verb should be completed to make the sentence is grammatically acceptable. This sentence can be completed by adding the main verb make.

In the above sentences, it is found that the students significantly tended to omit the main verbs of the sentences that should be put on the blank spaces. Because they omitted them, consequently the ideas of each sentence above are lost. It makes the accuracy of the sentences is low. So, scientifically, the quality of academic writing will be lower too than what it should be.

4. Omission of Direct Object

a. As soon as the teacher finishes the piece ..... , she/he should explain.(2-p.14);

b. The material should be presented by including variety activities to make ....... interesting, and the students have to be involved actively in the classroom, for example, funny story. (3-p.11).

In the above sentences, it is found that the students significantly tended to omit the direct object of the sentences that should be put on the blank spaces. Since the students omitted them, consequently the ideas of each sentence above are lost. It makes the accuracy of the sentences is low. So, scientifically, the quality of academic writing will be lower too than what it should be.

5. Omission of Grammatical Morphemes - article -the

a. Ask another students to do ...... same with her/his friend above and correct again. (5p.12);

b. Finally,....teacher rarely uses interesting activities to motivate ..... students to learn English. (7-p.3).

In the above sentences, it is found that the students significantly tended to ommit article-the of the sentences that should be put on the blank spaces. Since the students ommitted them, consequently the ideas of each sentence above is lost. It makes the accuracy of the sentences is low. So, scientifically, the quality of the academic writing will be lower too than what it should be.

6. Omission of Grammatical Morphemes-short plural -s

a. Ask the students to write short conversation and it contains about two or three tag question.... And practice the conversation in front of the class. (4-p.15);

b. Some definition ...... of reading and reading comprehension reflect a decoding emphasis. (8-p.6).

In the above sentences, it is found that the students significantly tended to omit the grammatical morphemes - short plural -s of the sentences that should be put on the blank spaces. Because they omitted them, consequently the ideas of each sentence above are lost. It makes the accuracy of the sentences is low. So, scientifically, the quality of academic writing will be lower too than what it should be.

7. Omission of Grammatical Morphemes - progressive/gerund -ing

a. The understand..... is the result of the process in the mind. (8-p.6);

b. It caused traffic jam and the drivers passing by showed their anxiety. (9-p.20). 
In the above sentences, it is found that the students significantly tended to omit the grammatical morphemes-progressive/gerund -ing of the sentences that should be put on the blank spaces. Because they omitted them, consequently the ideas of each sentence above are lost. It makes the accuracy of the sentences is low. So, scientifically, the quality of academic writing will be lower too than what it should be.

8. Omission of Grammatical Morphemes - plurality/singular third person

a. To practice reading aloud in the classroom, a teacher must prepare suitable materials and don't make the students bored. (7-p.9);

$b$. The teacher ask the students some question based on sentence. (9-p.23).

In the above sentences, it is found that the students significantly tended to omit the grammatical morphemes - plurality/singular third person of the sentences that should be put on the blank spaces. Because they omitted them, consequently the ideas of each sentence above are lost. It makes the accuracy of the sentences is low. So, scientifically, the quality of academic writing will be lower too than what it should be.

9. Omission of Grammatical Morphemes - infinitive marker to

a. So the students do not interest.... learning English. 7-p.2;

b. Usually teacher do not use media, once she/he must used interesting media to encourage the students .... learn English. (7-p.8).

In the above sentences, it is found that the students significantly tended to omit the grammatical morphemes - infinitive marker to of the sentences that should be put on the blank spaces. Because they omitted them, consequently the ideas of each sentence above are lost. It makes the accuracy of the sentences is low. So, scientifically, the quality of academic writing will be lower too than what it should be.

10. Omission of Grammatical Morphemes - regular past and passive form -ed

$a$. She/he can make a variation ways or give motivation to the story what it makes the student interst..... to read the text or the story after their teacher.(7-p9);

b. The problems are usually face.... by the teachers. (8-p.1);

c. The teachers can use many reading texts which are communicative to be use... (9-p.15);

d. This approach argues that languages exists in context are purpose..... for which of text and grammar.....(9-p.15).

In the above sentences, it is found that the students significantly tended to omit the grammatical morphemes-regular past and passive form -ed of the sentences that should be put on the blank spaces. Because they omitted them, consequently the ideas of each sentence above are lost. It makes the accuracy of the sentences is low. So, scientifically, the quality of academic writing will be lower too than what it should be.

\section{Discussion}

Based on the whole sentences above, there are some errors are found, in which, the students significantly tended to omit the grammatical components of the sentences. Because they omitted them, consequently, the ideas of each sentence above are lost. It makes the accuracy of the sentences is low. Consequently, the scientific quality of academic writing is low too, since 
there are more components of grammar are omitted than they should be. There is a need to review grammar as the theme that usually causes problems for learners. The areas are widely covered and are considered here.

Since the component of grammar is one of the indicators of the academic writing quality besides the organization of the writing, significantly it should be used accurately. Some of the grammar components which should be used accurately are: 1) Word order. A normal English declarative sentence has the following structure, with the subject preceding the predicate, 2) Agreement of Subject and Verb. The subject and the main verb of a sentence (clause) must agree in number, 3) Nouns Keeping Foreign Plurals. Plurals of the nouns of Latin, Greek, and Hebrew origin are often used in English scientific writing (Maclin, 1996) even though their English plurals may exist in general use, 4) Articles. English articles usually are widely taught. Below are the most basic rules of using articles that you should always observe: The Indefinite Article " $a$ " (before a consonant sound) or "an" (before a vowel sound) is used with countable nouns in the singular, meaning "member of a class of objects," "one of," "some", The Definite Article the is used with countable nouns in the singular/plural and uncountable nouns in the meaning "contextually known," "mentioned earlier," and The Zero Article. Usually, no article is used when a plural or an uncountable noun is mentioned first unless the special conditions for definite article use apply (Yakhontova, 2003).

The data analysis above can be corrected by the students' academic writings or thesis advisors before they were permitted to follow the final comprehensive exam. Since there are no serious and appropriate corrections by the advisors, it can be seen that the students are in serious problems in writing their academic writings or theses. The types of grammatical errors made by the students, in form of omission types, can affect the quality of their academic papers. It makes the academic writings or theses are in incomplete and unstructured ideas, so it makes the readers do not catch the complete ideas presented in those academic writings or theses.

The above errors were caused by the students' mother language interference. Most of the grammatical components in English are not presented in Indonesian so that the students tended to omit some of the English grammatical components when they have to write academic writings in English. However, the absence of some grammatical components of English in students' mother language can be learned intensively in grammar subjects, and integrated used and practiced in writing subjects. So, the absence of grammatical components of English can be integrated used by the students in writing their academic writings.

The language interference problem should be minimized immediately by the correction work of students' acadmic writing advisors too. It is related to the research finding conducted by Al-Yaari (2013), in which these errors were the effect of inter-language (L1 interference), the general order of difficulty (hierarchy of difficulty) which is applied to both L1 and L2, the morphemes theory that discusses what is learned before the other (as some morphemes are more difficult than others), and finally, we have intra-lingual (Target Language source like regular form: within the target language). Examples of intralingual sources include overgeneralization, incomplete applications of rules, and false concepts hypothesized. Nor must we forget to say 
here that redundancy reduction or false analogy is in a way similar to overgeneralization and one of the causes of it. However, addition and omission are also some types of redundancy (Al-Yaari, 2013).

Ideally, the students should not have such grammatical errors anymore, because they have had guidance and some corrections from their academic writings or thesis advisors who let them follow the final comprehensive exam. It needs recognized techniques used to guide students in the manner that they find their own mistakes. If the children have an interest in, and proficiency in writing, it is possible to teach them to find and analyze grammar mistakes (Uusen and Müürsepp, 2010: 170-184). A teacher does not correct the mistake but draws students' attention to it and allows them to correct it (Allahyar and Ramezanpour, 2011: 240-243).

These grammatical errors make their argumentative and interesting ideas in their academic writings are unapplied by the readers who are dominantly English teachers. It makes these academic writings become uninteresting ones to be read because it is difficult for the readers to understand the structure of it. So, highly serious attention to the grammar of the students' academic writings is suggested to the Grammar and Writing subjects lecturers, as well as to the students' academic writings or theses advisors.

\section{CONCLUSIONS}

Outcomes of this study show that the students make errors in major word classes as well as in minor word classes. Errors of major word classes include those of nouns in terms of head nouns, main subject, and the direct object. Consequently, errors are in major word classes in terms of main verbs. The same problems are found in errors related to the use of determiners, namely, articles. It is a question of agreement in determiners and numbers as well. Errors including quantifiers have been also observed. Finally, the students seem to have big problems with English grammatical morphemes. The causes are the absence of grammatical morphemes in their native language (L1). All of, the factors behind committing such errors by the students can be classified into two types, both linguistic and non-linguistic factors.

It is suggested to the Grammar subject lecturers and students' academic writing or thesis advisors to pay more attention to the students' errors. Both Grammar subject lecturers and students' academic writing or thesis advisors should correct the students' errors to minimize their errors because errors should be corrected.

\section{REFERENSI}

Allahyar, N., and Ramezanpour, S. (2011). No Extreme any More, Strike a Balance. Asian Social Science vol. 7, no. 5, pp. 240-243.

Al-Yaari, Sadeq Ali Saad. (2013). Written Grammatical Errors of Arabic as Second Language (ASL) Learners: An Evaluative Study. Macrothink Institute. International Journal of English Language Education, Vol. 1, No 2, Special Issue, ISSN 2325-0887.

Bailey, Stephen. (2004). Academic Writing: A Practical Guide for Students. London: Routledge 
Falmer.

Bailey, Stephen. (2006). Academic Writing: A Handbook for International Students. (Second edition). New York: Routledge, Taylor \& Francis Group.

Cameron, Lynne. (2001). Teaching Language to Young Learners. Cambridge: Cambridge University Press.

Darmouth, Institute for Writing and Rhetoric. http://writing-speech.darmouth.edu/

Dulay, Heidi, et al. (1982). Language Two. New York: Oxford University Press.

Frodesen, Jan. (1991). Grammar in Writing”. Murcia, Marianne Celce (Ed.). Teaching English as a Second or Foreign Language (p. 264). New York: Newbury House.

Hogue, Ann. (2008). First Steps in Academic Writing (Second Edition). New York: Pearson Education, Inc.

Ibrahim, M. M. M., \& Ibrahim, A. I. (2020). An Analysis of Grammatical Errors in Academic Writing of EFL Students. Asian Journal of Social Science and Management Technology, 2(6), 81-90. www.ajssmt.com

Maclin, Alice. 1996. Reference Guide to English: A Handbook of English as a Second Language. Washington: Materials Branch, English Language Programs Division

Quirk, Randolph, et al. (1985). A Comprehensive Grammar of the English Language. New York: Longman.

Uibu, Krista and Merili Liiver. (2015). Students' Grammar Mistakes and Effective Teaching Strategies. International Journal of Teaching and Education, Vol. III, No. 1/ 2015.

Uusen, A. and Müürsepp, M. (2010). Orthographic skills and teaching orthography in light of the renewed Estonian language syllabus. Problems of Education in the 21st Century, vol. 21, pp. 170-184.

Yakhontova, T.V. (2003). English Academic Writing for Students and Researchers. New York: Bureau of Educational and Cultural Affairs of the United States Department of State (ECA). 